\title{
SKILLS-BASED EDUCATION
}

\section{COMMENTARY}

\section{Improving the Remediation Process for Skills-based Laboratory Courses in the Doctor of Pharmacy Curriculum}

\author{
Jennifer S. Chen, PharmD, ${ }^{a}$ David E. Matthews, PharmD, ${ }^{\mathrm{b}}$ Jared Van Hooser, PharmD, ${ }^{\mathrm{c}}$ \\ Laura E. Knockel, PharmD, ${ }^{\mathrm{d}}$ Kim Lintner, PharmD, ${ }^{\mathrm{e}}$ Morgan Stoa, PharmD, ${ }^{\mathrm{a}}$ Jamie L. Woodyard, PharmD, \\ Deanna Tran, PharmD ${ }^{\mathrm{g}}$ \\ ${ }^{a}$ University of Minnesota, College of Pharmacy, Minneapolis, Minnesota \\ ${ }^{b}$ The Ohio State University, College of Pharmacy, Columbus, Ohio \\ ${ }^{\mathrm{c}}$ University of Minnesota, College of Pharmacy, Duluth, Minnesota \\ ${ }^{\mathrm{d}}$ University of Iowa, College of Pharmacy, Iowa City, Iowa \\ ${ }^{\mathrm{e}}$ University of Wisconsin - Madison, School of Pharmacy, Madison, Wisconsin \\ ${ }^{\mathrm{f}}$ Purdue University, College of Pharmacy, West Lafayette, Indiana \\ ${ }^{g}$ University of Maryland, School of Pharmacy, Baltimore, Maryland
}

Submitted October 29, 2020; accepted March 26, 2021; published August 2021.

\begin{abstract}
When students fail to meet minimum competence standards on summative pharmacy skills-based assessments, remediation can be used to ensure student readiness for progression. Skills-based remediation is challenging as a high volume of resources is required to develop an action plan that addresses the heterogeneity in student needs and to create and execute another assessment equivalent to the initial assessment. Although many Doctor of Pharmacy (PharmD) programs face these same challenges, there is no consensus on how to best address them. Recently, faculty from six PharmD programs convened to share ideas and approaches to overcoming these challenges. This commentary aims to define remediation as it pertains to summative skills-based assessments, share our consensus views regarding remediation best practices, and highlight areas where there is more work to be done. Our intent is to advance the ongoing conversation and empower institutions to develop their own effective and impactful skills-based remediation policies, procedures, and activities.
\end{abstract}

Keywords: remediation, skills, skills lab, competence

\section{INTRODUCTION}

Remediation is a "remedy to a problem or a process to correct an academic fault or deficiency." Remediation is distinct from reassessment. Although reassessment may be used at the end of remediation to confirm student competence, remediation by definition involves a process to remedy the deficiency in knowledge or skills. The Accreditation Council for Pharmacy Education (ACPE) Standards 2016 require Doctor of Pharmacy (PharmD) programs to have policies surrounding progression, including remediation. ${ }^{2}$ The Standards do not state what should be included in a remediation policy or what makes remediation effective. Published literature on remediation in PharmD programs reveals considerable variability in

Corresponding Author: Jennifer S. Chen, University of Minnesota, College of Pharmacy, 308 Harvard St. SE, Minneapolis, MN 55455. Tel: 612-624-2544. Email: chen0666@umn.edu remediation policies and procedures. ${ }^{1,3-5}$ To our knowledge, no published studies are specific to remediation in pharmacy skills-based laboratory courses, referred to as "skills labs" in this paper.

The application of this broad definition of remediation to skills labs differs from that used in other settings. While traditional classrooms evaluate the percentage of content answered correctly, skills labs must establish minimum competence benchmarks. These courses teach and assess professional practice skills using simulated activities and use performance-based assessments that require the student to demonstrate such skills. Currently, there is no consensus definition of remediation applicable to skills labs. There is little published on which pharmacy professional practice skills require remediation, what processes are most effective, or how to measure success.

Representative laboratory instructors from six PharmD programs met several times during the 2019- 


\section{American Journal of Pharmaceutical Education 2021; 85 (7) Article 8447.}

2020 academic year to share ideas and practices from their respective institutions as a start toward establishing consensus. We defined skills-based remediation as "a process to remedy unsatisfactory performance on a summative skill assessment implemented within a course with the intent of ensuring minimum competence prior to progression." In this commentary, we share the authors' ideas and experiences regarding skills-based remediation.

\section{DISCUSSION}

\section{Minimum Competence and Critical Skills}

Thresholds for passing grades on all summative skills-based assessments must represent minimum competence. A student's current year in the curriculum should be considered, with the goal of a student being prepared for advanced pharmacy practice experiences (APPEs) at the end of their didactic education. ${ }^{2}$ Regardless of the method used to establish thresholds, multiple faculty members at an institution should be involved in establishing minimum competence. Students who fail to meet minimum competence should undergo remediation, and remediation should be reserved to address only the most critical pharmacy practice skills indispensable for success in subsequent courses, introductory pharmacy practice experiences (IPPEs), APPEs, and professional practice. Examples of key skills that may warrant remediation include, but are not limited to, communication, pharmacy calculations, physical assessment, immunization, and application of the Pharmacists' Patient Care Process in various pharmacy settings. Reserving remediation for only critical skills balances the value of these activities with potential stress, burnout, and remediation fatigue among students and faculty.

\section{Grading Considerations}

Remediation policies should not remove students' incentives to meet the passing threshold on the first attempt. Allowing students to improve upon their grade but not exceed the minimum passing score may give them the motivation they need without incentivizing students to rely on a second attempt. A variety of approaches have been used to accomplish this goal. Five of the six programs represented by the authors of this commentary keep the original score in the gradebook and the student is required to undergo remediation for successful completion of the course. One program gives full credit (100\%) if a student passes the initial assessment; if a student does not pass, they are allowed a second attempt with a maximum possible score of $70 \%$. While passing scores should be setatminimum competence, grading schemes for remediation should be structured to ensure student investment in the original assessment. The students' goal should be delivering their best performance for every patient every time, as there is no opportunity to remediate patient care.

\section{Resources}

One key component of planning remediation involves allocating resources. Incorporating remediation into the class schedule helps account for faculty effort, students' schedules, and course resources. Five of the six PharmD programs represented by the authors designate one to two weeks at the end of the semester for remediation activities. Physical supplies for the semester must account for remediation, as any practice or mentoring sessions may require supplies in addition to the reassessment itself.

Additionally, remediation is not just an investment of physical resources, but also of faculty and staff time and effort. Time is required to develop practice activities tailored to the student and provide guidance and mentorship on the skill, in addition to developing, recruiting, and training skilled evaluators; proctoring; and evaluating the final reassessment. Skills such as administering immunizations or taking blood pressures may require additional personnel to conduct the remediation. Studies have shown that faculty spend from as little as 11 hours on developing and administering remediation activities for multiple students in a lecture-based course to as many as 100 hours on these activities for one APPE student. ${ }^{6,7}$ The time needed to implement skills-based remediation varies based on the skill being assessed; however, as skills labs often simulate experiential settings, the number of hours devoted to skills-based remediation is likely closer to that reported for experiential remediation. Because of the significant amount of time and resources required, it is important to estimate the number of hours needed for remediation to determine its feasibility. Developing a remediation policy that balances students' remediation needs with faculty effort helps to avoid burnout and ensures faculty can meet other academic responsibilities.

\section{Ideal Components and Characteristics of Remediation}

Critical components of the remediation process include reflection, practice, and demonstration of the skill in a reassessment, thus modeling the continuing professional development cycle as it applies to a specific activity and shifting it from an academic obligation to an impactful experience. After an initial evaluation warrants remediation, faculty can assist the student in reflecting, planning, and learning as they prepare to demonstrate their subsequent learning during remediation. This can standardize the process, although the final action plan should be individualized. 


\section{American Journal of Pharmaceutical Education 2021; 85 (7) Article 8447.}

A combination of factors, including lack of knowledge, limited skills, poor attitudes, and even life circumstances, may result in a student's unsatisfactory performance on an initial assessment. Discussion with the student will provide insights into which of these factors affected them the most, and faculty can provide additional professional practice perspectives and suggestions for improvement. Revelations by both parties may only come from discussing each vantage point and may help both the faculty member and the student when approaching future activities. Ideally, the learner is integrally involved in the remediation process and may even take the lead on developing an individualized action plan related to steps to be taken before, during, and after the remediation. Engaging both parties in discovering the root causes of unsatisfactory performance allows the plan to be more personalized, applicable, and rewarding. Such a plan promotes a growth mindset and softens the impact of having to complete a remediation activity by fostering the spirit of pursuit of ongoing excellence in patient care through better self-awareness. ${ }^{8}$

The practice component of this process should be meaningful and allow repetitions in various contexts to ensure transferability to professional practice. For example, a student remediating a patient interview exercise should ideally complete several practice encounters before the final reassessment to determine progression. Feedback should be provided after each practice session, and students should reflect on performance and lessons learned throughout the process.

Reassessment can ensure competence after the remediation process has been implemented. Instructors must ensure the reassessment is equivalent to the original assessment in difficulty and scope. Continuing the patient interview example above, the case used for reassessment should contain a similar number and type of medications and medication-related problems. Peer review by another faculty instructor can help ensure the reassessment case is similar in scope.

\section{Calls to Action}

Based on the authors' discussions and findings from collaborative study of the remediation process in pharmacy education, we issue the following calls to action:

1. Pharmacy educators and stakeholders should collaborate to establish a standardized set of critical pharmacy practice skills requiring remediation if not initially demonstrated satisfactorily.

As stated previously, remediation should include the critical skills required of students. Reserving remediation for only critical skills avoids burnout, stress, and remediation fatigue in both faculty and students, while maintaining the value of these activities. While ACPE Standard 17.2 requires colleges to adopt policies related to remediation, guidance on what skills are deemed critical is lacking. ${ }^{2}$ There is literature addressing essential skills and core professional activities to guide pharmacy instruction. ${ }^{9,10}$ However, remediating each of these skills in every student is impossible. As such, collective identification of such critical skills in which competence must be remediated prior to graduation may provide both guidance for remediation and greater consistency in assessment across programs.

2. Skills labs should support program-level processes to identify students at risk of failure early on and create interventions to minimize the need for remediation.

ACPE Standard 17.2 requires program-level monitoring of student performance to identify issues and provide appropriate intervention. ${ }^{2}$ Skills labs, which evaluate individual performance on practice-based skills, are well-positioned to support these processes. With regular monitoring, identification and resolution of issues can occur as early as possible to minimize the need for remediation. In skills labs, this system is particularly critical, and it should include regular feedback about student performance from teaching assistants and instructors, who can then arrange for additional focused, hands-on practice of skills and/or tutoring.

3. Programs should create policies to identify students who frequently remediate in order to identify and address underlying barriers or consider the students' fit for the program.

Programs should identify students who frequently need to remediate activities despite regular and early interventions and address any underlying barriers. If a student continues to require frequent remediation, whether they pass remediation or not, programs need a process to review and discuss with the student their fit for the program.

4. Programs should provide appropriate resource allocation for remediation activities.

As discussed above, in comparison to other courses, remediation activities in skills labs often require significant time, supplies, personnel and associated support to ensure effective remediation. Assessing the efficacy of these efforts is not only important for student progression, but also for the sustainability of any remediation policy. Resources used for these activities should be tracked and assessed in 


\section{American Journal of Pharmaceutical Education 2021; 85 (7) Article 8447.}

conjunction with assessing the efficacy of the remediation activities to ensure adequate support is in place.

5. Programs should monitor for effective and efficient remediation activities and collaborate with other programs to develop and share these activities.

When reviewing remediation practices in skills labs, programs should develop and implement a process of continuous quality improvement (CQI) to regularly assess the effectiveness and efficiency of remediation interventions. This will allow programs to ensure the interventions created to support students through the remediation process are functioning as anticipated and are resourced appropriately.

In addition to developing a CQI process to evaluate remediation effectiveness, programs are likely to benefit from collaboration around successful and effective remediation activities. Creating a process to share effective and efficient remediation activities reduces some of the resource-intensive development of remediation activities. Furthermore, collaboration with other programs to develop and assess remediation activities on a given skill would likely reduce resource burden while allowing faculty to implement previously effective remediation activities and/ or models.

Downstream performance is also a concern; ensuring students are appropriately and effectively able to demonstrate key skills will impact their success in future skills labs. Additionally, these essential skills likely impact student performance on IPPEs, APPEs, the North American Pharmacist Licensure Examination, and residency or job placement. Thus, programs should develop methods for tracking student performance downstream of the remediation activity intervention to ensure its effectiveness.

\section{CONCLUSION}

Remediation is a critical component of a successful PharmD program. Remediation has not been well-defined in the setting of pharmacy skills labs. In this commentary, the authors define skills-based remediation as a process to remedy unsatisfactory performance on a summative skill assessment, implemented within a course with the intent of ensuring minimum competence prior to progression. This process requires practice, feedback, and reassessment related to a predetermined skill. Because of the resource-intensive nature of remediation, critical skills and thresholds must be determined and student performance must be monitored regularly to support both students and faculty adequately. Furthermore, the effectiveness and efficiency of remediation efforts should be monitored to minimize resource utilization and ensure student progression.

\section{REFERENCES}

1. Maize DF, Fuller SH, Hritcko PM, et al. A review of remediation programs in pharmacy and other health professions. Am J Pharm Educ. 2010;74(2):25. doi:org/10.5688/aj740225.

2. Accreditation Council for Pharmacy Education. Accreditation Standards and Key Elements for the Professional Program in Pharmacy Leading to the Doctor of Pharmacy Degree ("Standards 2016"). Published February 2015. https://www.acpe-accredit.org/pdf/

Standards2016FINAL.pdf. Accessed March 17, 2021.

3. Harmon KS, Gonzales AD, Fenn NE. Remediation and reassessment methods in pharmacy education: a systematic review. Curr Pharm Teach Learn. 2021;13(1):81-89. doi:org/10.1016/j.cpt1.2020. 07.005 .

4. Hardinger K, Garavalia L, Graham MR, et al. Enrollment management strategies in the professional pharmacy program: a focus on progression and retention. Curr Pharm Teach Learn. 2015;7(2):199_ 206. doi:org/10.1016/j.cptl.2014.11.015.

5. VanLangen KM, Meny LM, Bright DR, et al. An initial environmental scan of APPE readiness assessment. Curr Pharm Teach Learn. 2020;12(7):771-775. doi:org/10.1016/j.cptl.2020.02.015.

6. Wang XR, Cruthirds DL, Kendrach MG. Effect of an individualized post-examination instructor remediation on pharmacy student performance in a biochemistry course. Am J Pharm Educ. 2018;82(6):6297. doi:org/10.5688/ajpe6297.

7. Martin RD, Wheeler E, White A, Killam-Worrall LJ. Successful remediation of an advanced pharmacy practice experience for an at-risk student. Am J Pharm Educ. 2018;82(9):6762. doi:org/10.5688/ ajpe 6762.

8. Dweck CS. Mindset: The New Psychology of Success. New York: Ballantine Books; 2008.

9. Frenzel JE, Nuziale BT, Bradley CL, et al. Using a modified delphi with skills laboratory faculty to define essential skills for pharmacy graduates. Am J Pharm Educ. 2020;85(2):848114. doi:10.5688/ ajpe848114.

10. Haines ST, Pittenger AL, Stolte SK, et al. Core entrustable professional activities for new pharmacy graduates. Am J Pharm Educ. 2017;81(1):S2. doi:10.5688/ajpe811S2. 